\title{
Different approaches in low-cost housing design and construction
}

\author{
D. Aureli \\ Dipartimento di Architettura, Università degli Studi Roma Tre, Italy
}

\begin{abstract}
Projects by Laurie Baker, Fabrizio Carola, and Samuel Mockbee, three architects whose work is generally considered under the "Low-Tech" label, are especially representative of the evolution of "appropriate technology" as defined by Anthony Akubue in further developing the theory of "intermediate technology" articulated E. F. Schumacher in the 1960s. Javier Mozas, in his essay "The Technological Choice" as an outlook on the world, defines the 1960s' term intermediate technology as an alternative to the High-Tech approach described by Peter Cook and Frei Otto during the same period. The implication being that appropriate technology and Low-Tech are not second-best options but the most appropriate response to a project's socio-economic environment. The two approaches, readymade and made in-situ, which can be found in projects by the three architects, can be considered Low-Tech options selected to minimise environmental impact in the design-build process. One approach uses decontextualized, reinterpreted elements, the other a careful selection of material available within few kilometres. LowTech, minimisation achieved through in-depth investigation, is geared to guaranteeing appropriate standards of building performance.

Keywords: appropriate technology, low-cost, small-scale, ready-made, made in situ, low-tech, local materials, sustainability pillar.
\end{abstract}

\section{Introduction}

While architecture has always incorporated a broad range of technologies, depending on the architect's expertise and the technological development of the country in question [1], two events in 1965 led to today's awareness that the degree of technology employed in architecture is more a question of ideology than a condition of the available information regarding possible building materials and 
methods of construction: the government of Peru and the United Nations invited British architect Peter Land to design a strategy for mass housing as an alternative to the massive informal settlements then overtaking Lima [2]; and E. F. Schumacher and a group of economists in London founded the Intermediate Technology Development Group (ITDG) [3]. These two separate and seemingly unrelated events were important in later developments and highly significant in defining the relationship between architecture and technology.

Taken together, the experience of low-cost housing in Lima (on the architectural side), and the development of the concept of appropriate technology [4] (on the economic side), were part of the same cultural ferment. That ferment created a new environmental awareness in the 1960s, even before the 1973 oil crisis and the 1972 Meadows report, widely regarded as one of the first to define the concept of sustainable development.

This was the start of a process that led to identifying Low-Tech as a key concept in sustainable development; a non-reductive alternative to High-Tech approaches. It could be said that the long path leading to today's understanding that both categories, High and Low, as applied to the concept of technology, began in 1965. This indicates not only greater or lesser sophistication in the industrial process required to produce a given item, but a fundamentally different world vision. Just as High-Tech is represented by a range of approaches and constructive philosophies, the same can be said for today's vibrant and multifaceted Low-Tech scene.

Within this context, this paper presents three similar yet different examples. This cross-section of possible Low-Tech approaches, while not exhaustive, speaks to the relationship between technological choices and environmental sustainability. Additionally, three examples of each of the two categories, readymade and made in-situ [5], illustrate the extent of Low-Tech architecture's panorama.

\section{Proyecto Experimental de Vivienda (experimental housing project)}

In-depth discussions with the Peruvian government, initiated in 1965 by Peter Land after following the government's invitation, culminated in the $1969 \mathrm{draft}$ brief for a design competition for an experimental housing project, Proyecto Experimental de Vivienda (PREVI).

The competition, intended to promote a new housing policy for the country, called for high density, low-cost housing for a community of 1,500 families. Thirteen Peruvian architects and a group of internationally famous designers, all with extensive experience in social housing, were invited to submit projects. Participating architects and firms included Georges Candilis, Atelier 5, Aldo van Eyck, James Stirling, Charles Correa, Christopher Alexander and the Japanese Metabolists group Kikutake-Kurokawa-Maki, all well-known representatives of the discipline's avant-garde.

The ambitious program proposed public housing projects along with community amenities such as schools, sports centres, community services and 
infrastructure. Pedestrian and vehicular traffic were to be separated and houses designed in clusters. The units themselves were to be expandable, accommodating up to eight children and three adults [6].

Partially due to Peru's political uncertainties at the time, the outcome of the competition was controversial. However, from a historical point of view, the crucial aspect was that for perhaps the first time the concept of low-cost housing appeared as a given programmatic element in a complex building program. Considering the calibre of the designers involved, specific requirements contained in the brief made it even more interesting.

In fact, in addition to the concepts of low-cost and high density, references were made to ideas of human-scale, the quality of urban spaces, the importance of pedestrian open spaces in neighbourhoods, and mixed use facilities, all of which were animating urban planning debates at the time. The competition brief transposed criticism of the modern movement in an attempt to provide a practical response to the demand for an improved quality of life in urban areas. All this happened in a developing country, in one of the poorest areas of its capital, making the entire exercise even more courageous and meaningful.

\section{Intermediate technology}

Schumacher and his colleagues George McRobie, Mansur Hoda, and Julia Porter founded the Intermediate Technology Development Group (ITDG) in the same year, 1965. Before theorising about the concept of intermediate technology, Schumacher, a well-established economist, worked for the British Treasury with John Maynard Keynes. He was also the Chief Economic Advisor to the National Coal Board of Britain for twenty years and thus was fully acquainted with problems related to energy and environmental sustainability.

In 1955, Schumacher went to Burma as an economic adviser for the United Nations, assisting the country's Prime Minister. In Burma, coming into contact with a new reality, completely different from Europe's, Schumacher began to see the world from a different perspective. His meeting with Gandhi and the study of Gandhi's economic theories shaped a new way of thinking.

Modern industry, developed in societies rich in capital and short on labour, is not appropriate for those short on capital and rich in labour. In such societies employment possibilities need to be created in the areas where people live, and not primarily in metropolitan areas. Production methods employed must be relatively simple, minimising demand for highly skilled labour, not only in the production process itself but also in terms of organisation, the supply of raw materials, financial and marketing issues. Production should be mostly from local materials and mainly for local use. These requirements can be met only through a regional approach to development and a conscious effort to develop and apply what can be referred to as an intermediate technology [7].

Intermediate technology was conceived with the intent of creating a new way of understanding development, which is more suitable to the world's poorest regions. To avoid the risk of the concept sounding like a second rate technology, in 1968 the Intermediate Technology Development Group adopted the phase 
appropriate technology. The new name, removing the suggestion of inferiority, included cultural and social dimensions in researching development and innovation [8].

Appropriate technology is a way of defining innovation most suited to developing world regions according to a paradigm of people-centric values, including everything small-scale, decentralised, labour-intensive, energyefficient, environmentally sound, and locally controlled.

\section{The three case studies}

Peter Land's low-cost housing and Schumacher's appropriate technology are complementary and can be considered the dual core of the Low-Tech movement, as illustrated in three case studies.

Three architects, unconsciously or instinctively, embraced the architectural precedents inherent in the PREVI project and the economic theories of ITDG. Their lives have certain similarities; all were born and raised in wealthy communities before moving to poorer regions in the world and reformulating their ideas on architecture.

Our interest in their experiences, however, lies not only in the uniqueness of the protagonists, all somewhat quirky personalities, but also in the specifics of their professional careers. Each can be considered an interpreter of one of the three pillars of sustainability: economic, environmental and social. Combined in proper balance the three pillars create a sustainable system [9].

In relating the experiences of Samuel Mockbee, Laurie Baker and Fabrizio Carola, each of the three pillars will be given special attention according to the given situation and project location.

\subsection{Social pillar}

Born in Mississippi in 1944, Samuel Mockbee's work was heavily influenced by his personal experience of the treatment of the African-American population in his home state. Having graduated from Auburn University's School of Architecture in 1977, in 1992 he returned as professor, immediately taking the opportunity to create a program that would give his students an awareness of the plight of the rural poor. Together with D. K. Ruth he founded the Rural Studio program, a university project directly involving students in both the design and construction of low-cost housing for poor communities in Hale County, Alabama.

When Mockbee founded the Rural Studio in the early 1990s, American architecture had all but retreated from social and civic engagement, turning more towards a preoccupation with style. Famous architects, swept up in the new global economy and captivated by new technology, designed increasingly audacious buildings for international affluent clients. Instead, Mockbee dug in at home in the Deep South, focusing on the design and construction of modest, innovative houses for the poor [10].

For over 20 years, continuing after Mockbee's death, Rural Studio has trained hundreds of students, constructing more than 80 houses and public buildings in 
Hale County. At the heart of Rural Studio's mission is the search for an originality of form and matter. Having no clear formal references, architectural or technological, the educational mission devised by Mockbee was the creation of a new ground zero for rural architecture in Alabama.

Rural Studio invites students to design with extreme originality while forcing them work within severely reduced budgets. Most of the studio's projects are characterised by the use of recycled, reused material: car license plates, newspapers, car windshields, old doors and wooden planks. Form as well as material is interpreted in new and unexpected ways.

In considering social issues and providing adequate responses from an economic and environmental point of view, Rural Studio also created an original model for public participation by involving both students and local citizens. Buildings designed to meet social needs, such as housing, community centres and fire stations, take into account local economics and environment sustainability, using a variety of recycled materials to the greatest extent possible.

\subsection{Economic pillar}

British-born architect Laurie Baker arrived in India in 1945 to work on building leprosy centres. During his time spent in the country's poorest regions he became fascinated by how villagers were able to create real architectural structures despite the poverty of their means. Baker decided to stay in India and study local construction with the aim of understanding the building techniques being implemented, and where possible, use his experience and knowledge to improve them. In 1985, he founded the Centre of Science and Technology for Rural Development, Costford, a non-profit organisation for low-cost housing. In particular, the Costford Centre focuses on encouraging local planning and development, empowering communities, creating multi-disciplinary technical support teams, and serving as a conduit for appropriate technology selected according to climate, culture, and available resources.

Baker promoted alternative technologies (such as the use of mud) to exploit materials available in large quantities in the Kerala area, reducing construction costs and making housing affordable to all. Also through Costford, Baker publishes and distributes free, educational material describing both its philosophy and alternative technologies.

Particularly significant is a series of detailed booklets describing the construction schemes Baker studied over the years, extremely useful to inexperienced builders attempting to construct low-cost homes. Construction details for creating controlled openings in brick walls instead of installing windows and expensive architectural elements, are especially interesting. Baker's work has had great resonance in India and has won numerous awards.

\subsection{Environmental pillar}

Fabrizio Carola, an Italian architect, was born in Naples. At 18 Carola moved to Belgium where he graduated from the School of Architecture "La Cambre" in 1956. Between 1961 and 1963, working as an urban planner in Morocco, he 
designed agricultural and rural projects. In 1971, he travelled to the sub-Saharan region of Mali to work as the project manager on the restructuring of the dike and buildings at the Mopti river port. More than 40 years later, Carola is still working in the region.

In Mauritania, Carola studied the ancient Nubian compass technique, rediscovered and used by Hassan Fathy for building domes of fired brick or clay. Carola immediately adopted this ancient technique, modifying and adapting it to the needs of various projects. The modified compass allows the construction of pointed domes, more spacious and liveable, with improved climatic behaviour thanks to Carola's adaptation devised to meet contemporary needs, namely the use of the double-shell. From then on the pointed dome marked the entirety of Carola's work.

In 1978, the European Development Fund (EDF) commissioned the architect a technical study for the design of the Kaedi hospital in Mauritania. The accepted project was then transferred to ADAUA, a Swiss NGO. The non-governmental organisation hired Carola to manage the hospital's construction, prompting his move to Mauritania in the late 1980s. On arriving in Kaédi, Carola realised that the project developed in Paris was inadequate and proceeded to completely rework the design before resubmitting it to the Mauritanian government and the EDF in the country's capital, Nouakchott. The new project was approved and construction began with bricks produced entirely on site. Two furnaces fed with rice chaff, a by-product of rice processing which otherwise went unused, made the production of thousands of bricks possible. The system allowed Carola to create a complex structure with a very low environmental impact and a positive impact on the local economy; 75 percent of the resources used were invested in the site.

\section{Ready-made and made in situ}

In each of these three examples special attention is paid to one of the three pillars of sustainability. Unavoidably, the other pillars also come into play, fulfilling crucial roles in the architectural projects. As with the concept of sustainability, the balance between the three pillars determines the sustainability, or lack thereof, inherent in the system. This illustrates the close relationship between Low-Tech architecture and sustainable development while confirming the necessity of having in-depth knowledge of the dynamics of each particular site. In-depth research and knowledge allows the designer to discern which pillar to focus on, and which technological approach is more appropriate.

The design and technology decisions manifested in the three cases discussed here are determined by two factors. On one hand, objective elements acquired through knowledge of the project's location; on the other, subjective concerns deriving from the architect's individual attitudes and sensibilities.

A profound awareness of place is the common starting point for all three cases. In-depth knowledge regarding readily available low-cost resources as well as a clear understanding of both the people involved in construction and those that will actually use the building after construction are essential. These factors, depending 
on the country where the project is being built, and the physical, cultural and economic characteristics particular to the site, can differ significantly.

Other than an acute understanding of place and existing social and economic dynamics, the designer's own sensitivity and awareness plays a fundamental role; their own lives, experiences and attitudes are also determining factors.

The combination of an in-depth knowledge of the site and the sensibilities of each architect determine the type of technology to be used. In line with the precepts of appropriate technology and low-cost design, technology is geared to achieving a sustainable construction process in consideration of the site's specific reality.

Made in-situ, an approach closely linked to the dictates of appropriate technology, is most commonly found in developing countries. The strategy is often based on recovering local building traditions and usually consists in using readily available and user-friendly raw materials.

Ready-made is an approach more often found in industrialised countries, where there is a production surplus available for reuse. This strategy can also be based on the use of low-cost industrial products purchased for the construction of a building although not originally produced for that specific purpose.

In comparing the two approaches, ready-made and in-situ, the words "contextualise" and "decontextualize" in terms of construction materials come into play. One approach uses decontextualized, reinterpreted elements; the other a thoughtful, careful selection from the means available within a few kilometres.

In light of this, the three experiences presented represent the two approaches, albeit each in a different way. The work by the three architects, vastly different, like many in the wide panorama of Low-Tech architecture, can be interpreted in this context.

Laurie Baker's work in India, although varied and always unique in form, is characterised by continuous and careful research in order to identify all the lowcost, available material in the agricultural land around Kerala where most of the projects are located. Alongside this research, Baker carried out an extensive programme of making low-cost construction manuals readily available to the community. Baker's aim was to create conditions allowing Kerala's rural population to build their own low-cost homes using local materials. The key objective being the use of local labour and materials and simplified building techniques.

Instead, for most of his work in Africa Fabrizio Carola uses an ancient Nubian building technique, reinterpreted to adapt to bioclimatic conditions. The idea of using rice chaff to fire brick kilns built on the construction site, attests to the continuous research carried out and dedicated to achieving ever greater economic and environmental sustainability in his projects. Carola, by taking his research to the furthest extreme, has been able to create a closed productive circle within the construction site itself.

Rural Studio's projects, mostly in agricultural areas in Alabama, are the expression of a collective that always approaches the design project at hand in unique and different ways. Homes, community centres and sports facilities become opportunities to experiment with new materials and new ways of assembling the most disparate constructive elements. Bales of cardboard to be 
recycled, old tires and used timber; every kind of reusable material or object is treated with dignity and given the possibility of a second life, especially important given the scarcity of resources.

From the three cases considered, one could define both Laurie Baker's and Fabrizio Carola's as made-in-situ, although with very different design choices. Similarly, the Rural Studio approach could be defined as ready-made. The raw earth architecture and bricks made by Baker in India and Carola's pointed domes in Africa have a common language; natural raw material used by reinterpreting traditional techniques while improving productive potential. On the other hand, houses built by students at the Rural Studio are a manifesto against the waste of raw materials, against throwing away material reusable in a thousand different ways.

Differentiating between these two approaches can seem deceptively easy but neither is a measurable or scientifically demonstrable entity.

\section{Conclusions}

Many different ways of interpreting, achieving and defining the idea of Low-Tech have emerged over the years, variations depending on the architects and locations of the projects. All are clearly valid and useful in determining the variants within the panorama of Low-Tech. In discussing Low-Tech as an expression of technology and low-cost construction, the different design solutions can be characterized in terms of style, material, or processes. Concerning architectural language, a distinction can be made between the regional reinterpretation of $\mathrm{B}$. $\mathrm{V}$. Doshi and Anna Heringer and the essential brutalism of Alejandro Aravena and the Lacaton-Vassal firm. Considering materials, a comparison can be established between the pioneering experimentation by N. John Habraken with glass bottles and old car parts, with the vast array of projects made of mud and straw, and LOTEK's success in using shipping containers.

The attempt here, however, is to identify a new way of interpreting this diverse panorama. The aim is to introduce the two categories, made in-situ and readymade, easily understood but evocative of the complexity inherent in Low-Tech architecture; a new, if allusive, interpretation is made of the processes behind design solutions as well as the final results of Low-Tech projects. Identifying LowTech architecture as made in-situ or ready-made means associating a specific architecture with a specific design philosophy. There is no point, however, in the definition being absolute; just as the concept of appropriate technology is relative to the site's location, and the concept of low-cost differs in relation to the particular situation; the ability to identify a project as belonging to one category or another must be relative.

In this sense, understanding the extreme flexibility of the two categories is essential; these are not rigid categories but relative to the scale of observation and the projects being compared.

The work of Rural Studio is a clear example. Comparing the studio's work to Carola's and Baker's, we identified the approach as ready-made. The same cannot be said, however, when considered on a larger scale or within a broader sphere of 
projects. Comparing the Rural Studio's projects to solar greenhouses, agricultural silos or container structures, prompts a different interpretation of their work. In comparison with such commonly found projects, widely considered Low-Tech architecture, we could consider Rural Studio's work, characterised by a careful selection from means available within the range of a few kilometres, as using a typically made in-situ approach as opposed to a ready-made one.

Made in-situ and ready-made are changeable and multifaceted categories which need to be considered within the complex reality in which they appear. Our intention is to explain the possibility of differentiating between Low-Tech architectural projects using the two categories. Although not an absolute yardstick, this attempt is geared to analysing projects through an understanding of the technological, cultural and economic resources that distinguish a particular site.

\section{References}

[1] Mozas Lérida, J., The technological choice as an outlook on the world. $a+t$ Magazine, 2(9), 1997.

[2] Ramis, T., A contemporary approach to the Proyecto Experimental de Vivienda in Lima. dAP - Digital Architectural Papers, 2(9), 2012.

[3] Akubue, A., Appropriate technology for socioeconomic development in third-world countries. Journal of Technology Studies, 26(1), 2000.

[4] Willoughby, K.W., Technology Choice: A Critique of the Appropriate Technology Movement, Westview Press: Boulder, CO, 1990.

[5] Aureli, D., Low, Bold Approaches Measured Architecture, L'Erma di Bretschneider: Roma, 2014.

[6] Khan, H., Cantacuzino, S. \& Correa, C., Charles Correa: Architect in India, Butterworth Architecture: London, pp. 52-55, 1987.

[7] Schumacher, E.F., Small is Beautiful: Economics as if People Mattered, Harper \& Row: New York, pp. 175-176, 1973.

[8] Pellegrini, U., The problem of appropriate technology. Criteria for Selecting Appropriate Technologies under Different Cultural, Technical and Social Conditions, eds A. De Giorgio \& C. Roveda, Pergamon Press: New York, pp. 1-5, 1979.

[9] United Nations General Assembly, 2005 World Summit Outcome, Resolution A/60/1, adopted by the General Assembly on 15 Sep. 2005.

[10] Oppenheimer, D.A. \& Hursley, T., Rural Studio: Samuel Mockbee and an Architecture of Decency, Princeton Architectural Press: New York, p. 12, 2002. 